\title{
Dois padrões de política cambial: América Latina e Sudeste Asiático ${ }^{1}$
}

\author{
Paulo Gala ${ }^{2}$
}

\section{Resumo}

Vários trabalhos empíricos têm encontrado uma relação negativa entre desalinhamento cambial e crescimento econômico para uma longa série de países nos últimos trinta anos; quanto mais depreciada a taxa de câmbio, maiores as taxas de crescimento. Nessa literatura, um tema recorrente é a relativa depreciação das moedas asiáticas quando comparadas às moedas latino-americanas e africanas. Nos diversos estudos, surge o resultado de maior depreciação para a Ásia, no que parece constituir um padrão de comportamento dos níveis de taxa de câmbio real para essa região. Com o objetivo de contribuir para a discussão, este trabalho compara a evolução dos níveis de taxas de câmbio reais para países da Ásia e América Latina no período 1970-1999. Discute aspectos do manejo cambial de alguns dos principais países dessas duas regiões e apresenta considerações sobre o papel da política cambial no processo de desenvolvimento destas duas macro-regiões.

Palavras-chave: Desenvolvimento econômico; Taxa de câmbio - Nível; Política cambial - América Latina; Sudeste da Ásia.

\section{Abstract \\ Patterns of exchange rate policy: East Asia versus Latin America}

Some authors argue in favor of a real exchange rate targeting strategy for developing countries in what could be called a development approach to exchange rates. According to the argument, relatively undervalued exchange rates have been a key factor in most East and Southeast Asian successful growth strategies. Following this so-called development approach, the objective of the paper is to compare the path of exchange rate levels in Asia and Latin America from 1970 to 1999. The work reviews some aspects of exchange rate management for some countries in those regions based on several case studies. It also presents an evolution of real exchange rate levels for a set of 20 countries based on World Bank data and on an index of exchange rate distortion.

Key words: Exchange rate levels; Growth; Latin America; East and Southeast Asia. JEL O11, F31, F4.

\section{Introdução}

Estudos sobre política cambial ocupam hoje um enorme espaço nas discussões macroeconômicas. As crises financeiras dos 1990, iniciadas com a ruptura do sistema monetário europeu em 1992 e concluídas com a crise Argentina, já em 2001, deram origem a uma vasta literatura sobre o tema.

(1) Trabalho recebido em maio de 2006 e aprovado em dezembro de 2006.

(2) Da Fundação Getúlio Vargas (FGV/SP). Agradeço os comentários de dois pareceristas anônimos da revista Economia e Sociedade.

Economia e Sociedade, Campinas, v. 16, n. 1 (29), p. 65-91, abr. 2007. 
Contudo, apesar do enorme avanço das técnicas econométricas e qualidade dos bancos de dados e da existência de um amplo rol de conceitos desenvolvidos ao longo do século XX, muitas das principais questões da literatura continuam sem respostas consensuais. A desregulamentação dos mercados financeiros nos últimos anos e a decorrente transformação da taxa de câmbio num ativo financeiro tornou as discussões ainda mais complexas. Inúmeras frentes de pesquisa florescem na literatura que trata de questões cambiais, desde a discussão sobre mercados financeiros e a formação da taxa de câmbio no curtíssimo prazo até os possíveis efeitos que o nível do câmbio real pode ter em trajetórias de crescimento econômico.

Dentro dessa discussão, vários economistas têm chamado a atenção para a importância da competitividade da taxa de câmbio real no processo de desenvolvimento econômico. Ao exercer impactos em processos de aumento de produtividade e investimento, o nível da taxa de câmbio real torna-se uma variável-chave para a promoção do crescimento. Muitos autores têm se referido, portanto, à competitividade da taxa de câmbio e à política cambial como uma importante "ferramenta" a ser utilizada por governos em estratégias de desenvolvimento. Além de evitar crises no balanço de pagamentos, um câmbio relativamente desvalorizado pode fornecer estímulos para aumentos de investimento e poupança, impactando o processo de acumulação de capital. ${ }^{3}$ Quanto à questão de inovações tecnológicas e "industrial upgrading", um câmbio competitivo pode gerar impactos positivos para o resto da economia a partir do estímulo à produção de manufaturas para exportação. ${ }^{4}$

Num importante trabalho sobre o tema, Williamson (2003) propõe um "development approach" para a política cambial, ressaltando a importância da utilização do câmbio como ferramenta para a promoção do desenvolvimento. Um câmbio competitivo seria importante para o desenvolvimento econômico, pois estimularia a indústria de exportações de bens não tradicionais, especialmente as manufaturas. Ao tornar rentável a produção de bens não "commodities" para o mercado mundial, um câmbio competitivo seria capaz de desencadear dinâmicas de desenvolvimento evitando o conhecido problema da "Dutch Disease". Países ricos em recursos naturais teriam dificuldades em desenvolver uma indústria exportadora de manufaturas por conta do excesso de fluxos de divisas e apreciações cambiais decorrentes das exportações de "commodities". O caso da Venezuela é um bom exemplo. As altas reservas de petróleo dificultaram sistematicamente seu processo de desenvolvimento. A Indonésia, por outro lado, surge como um bom exemplo de superação da doença holandesa a partir de uma eficiente administração macroeconômica.

(3) Ver Bresser-Pereira (2006, p. 3).

(4) Ver Williamson $(2003,2005)$. 
De fato, vários estudos mencionam a importância da manutenção de câmbios competitivos em casos de crescimento econômico sustentável. Rodrik (2000), por exemplo, trata dessa questão antes de discutir os impactos de arranjos institucionais e abertura da conta capital para países em desenvolvimento. Após ressaltar os casos de sucesso do Chile (meados dos anos 1980), Turquia (início dos 1980), Índia (início dos 1980 e desde 1994), Uganda (desde 1986), e Ilhas Maurício (meio dos 1980), conclui que seria importante investigar as possíveis consequiências positivas de uma depreciação do câmbio real sobre o crescimento de longo prazo de economias emergentes. No estudo "Growth Accelerations", em conjunto com Hausman et al. (2004), encontra resultados empíricos importantes a esse respeito. Ao analisar um total de 80 transições de baixo para alto crescimento em países em desenvolvimento desde os anos 1960, encontram a depreciação do câmbio real como um fator importante para o início do processo (Hausman et al., 2004, p. 16).

No atual arranjo de crescimento "desequilibrado" da economia mundial, a subvalorização das moedas asiáticas em relação ao dólar americano também merece atenção. Um dos pilares do crescimento liderado pelas exportações na Ásia tem sido a administração da competitividade de suas moedas. Dooley et al. (2003), por exemplo, analisam a estratégia recente da China e de alguns países asiáticos de crescimento com câmbio subvalorizado. A rota de "export-led growth" seguida pelos asiáticos replica o arranjo de Bretton Woods quando o marco alemão, a lira italiana e yen japonês foram fixados em níveis subvalorizados para ajudar na reconstrução do pós-guerra. Ao tornar a moeda local altamente competitiva, um câmbio relativamente desvalorizado tem contribuído para grandes taxas de investimento e crescimento na China. Essa estratégia tem sido funcional para o desenvolvimento de toda a região do Leste e Sudeste Asiático nos últimos vinte anos. $^{5}$

Existe também hoje uma importante literatura econométrica que procura relacionar taxas de crescimento econômico com a administração cambial e níveis de taxa de câmbio real. Em trabalhos sobre o tema, Cavallo et al. (1990), Dollar (1992) e Razin e Collins (1997) encontram uma relação negativa entre desalinhamento cambial e crescimento econômico para uma longa série de países no período 1970-1990; quanto mais depreciada a taxa de câmbio, maiores as taxas de crescimento. Benaroya e Janci (1999) apresentam evidências para países em desenvolvimento nos anos 1990 que confirmam os resultados de Dollar (1992). Acemoglu et al. (2002) encontram evidências semelhantes entre câmbio real e crescimento. Num trabalho sobre instituições, políticas macroeconômicas e crescimento com 96 países de 1970 a 1997 não conseguem descartar o efeito do câmbio real em variações da taxa de crescimento per capita dos países ao longo do

(5) Ver Dooley et al. (2005, p. 5).

Economia e Sociedade, Campinas, v. 16, n. 1 (29), p. 65-91, abr. 2007. 
tempo. Fajnzylber et al. (2002) encontram resultados parecidos ao estudar o crescimento comparado das economias latino-americanas e de outros países no período 1960-1999. Em toda essa literatura, um tema de discussão recorrente é a relativa depreciação das moedas asiáticas quando comparadas às moedas latinoamericanas e africanas no período 1970-1999. Nos diversos estudos citados, o resultado de maior depreciação para a Ásia surge, no que parece constituir um padrão de comportamento dos níveis de taxa de câmbio real para essa região. Para os casos africano e latino-americano, o padrão parece ser o oposto. Ciclos de apreciação são constantes e vários estudos empíricos sobre América Latina apontam nesse sentido.

Seguindo este debate, a principal hipótese a ser testada neste estudo é a de relativa depreciação das moedas asiáticas quando comparadas às latino-americanas nos últimos trinta anos. Para tanto, o trabalho analisa a evolução dos níveis de taxas de câmbio real para países da Ásia e América Latina no período 1970-1999, tomando por base uma série de estudos de caso e diversas tentativas (sempre controversas) de mensuração de nível do câmbio real. Discute, ademais, aspectos do manejo cambial de alguns dos países dessas duas regiões. Vale ressaltar também que a maioria da literatura que trata do sucesso do Sudeste Asiático se baseou, durante muito tempo, em aspectos da política industrial e tecnológica na região, não se atendo a importantes aspectos macroeconômicos desse processo. Uma das novidades deste trabalho é, portanto, apontar para a importância do desenho da estratégia macroeconômica no desenvolvimento desses países, especialmente no que diz respeito à condução da política cambial.

O texto se divide em 3 seções, além desta introdução. A seção 1 apresenta alguns ciclos de apreciação na América Latina nos anos 1970, 1980 e 1990, se concentrando nos conhecidos casos de populismo cambial dos anos 1970 e 1980 e nos aspectos da política cambial dos três principais planos de estabilização da América Latina nos anos 1990: México, Argentina e Brasil. A seção 2 se concentra nos países asiáticos com destaque para a estratégia de "export-led growth" seguida principalmente por Taiwan, Coréia do Sul, Hong Kong e Cingapura desde os 1970, Malásia, Indonésia e Tailândia a partir dos 1980 e, mais recentemente, China. A seção 3 apresenta tendências do comportamento do câmbio real para essas duas regiões e finalmente algumas conclusões.

\section{Sobrevalorizações na América Latina}

A partir da crise da dívida no início dos anos 1980, o padrão de crescimento das economias latino-americanas se distanciou de seu registro histórico. Países como Brasil e México que exibiam altas taxas de crescimento per capita até então entram num ciclo de "stop and go" que persiste até hoje. Com a exceção do Chile e possivelmente Colômbia, o desempenho dos países da região 
nos 1980 e 1990 ficou muito aquém de seu desempenho histórico. Nesse período mais recente de crescimento cíclico e inflação fora de controle, dois elementos são comuns à maioria dos países latino-americanos: populismo e planos de estabilização com ancoragem cambial. Com efeito, os países da América Latina são conhecidos por sua longa tradição de populismo econômico que traz em seu bojo descontroles orçamentários e ciclos de apreciação cambial. Crises no balanço de pagamentos e processos inflacionários crônicos são constantes latinoamericanas. A sobrevalorização cambial e a indisciplina fiscal foram dois ingredientes básicos em sua história recente, especialmente quando comparados com países do Leste e Sudeste Asiático.

A sobrevalorização cambial foi também largamente utilizada em países da América Latina no período de substituição de importações para estimular a industrialização substitutiva de importações (ISI). Funcionava como uma forma indireta de taxação sobre a exportação de "commodities". Transferia para o setor industrial parte dos lucros auferidos pelas exportações agrícolas que se beneficiavam do elevado nível de preços dos bens primários. Entretanto, a partir da consolidação da industrialização, a estratégia passou a ser contraproducente na medida em que dificultava a penetração dos produtos latino-americanos no mercado internacional. Os ciclos de apreciação decorrentes dos episódios populistas e de estabilização tiveram graves consequiências no desenvolvimento do setor de bens comercializáveis não tradicional da região. Como destacam alguns autores, a sobrevalorização cambial deixou de ser funcional para o desenvolvimento da América Latina como na fase de industrialização substitutiva de importações (ISI) na década de $1970 .^{6}$

Em relação ao populismo econômico há em economia uma definição distinta do tradicional conceito de populismo utilizado na ciência política, associado à idéia de líderes carismáticos que governam junto ao povo sem o intermédio de partidos políticos. Governos que praticam déficits orçamentários recorrentes como conseqüência de aumentos salariais acima da produtividade do trabalho ou ainda que promovem apreciações cambiais com o intuito de aumentar os salários reais, estariam incorrendo em populismo econômico. Melhoram o bemestar dos trabalhadores no curto prazo com vistas ao ciclo político sem levar em consideração as conseqüências de longo prazo de tais políticas. A lógica populista produz distorções com efeitos benéficos no curto prazo à custa de grandes desajustamentos no longo prazo. O desalinhamento da taxa de câmbio no sentido de sobrevalorização é uma poderosa ferramenta de aumento de salários reais sem contrapartida de mudanças estruturais adequadas na economia. A redução de preços dos bens comercializáveis em relação aos não comercializáveis, especialmente salários nominais, representa um significativo aumento de salário real.

(6) Ver, por exemplo, Fishlow (2004, p. 228). 
O excesso de demanda provocado por políticas populistas não tem uma contrapartida em aumento da capacidade produtiva. $\mathrm{O}$ esgotamento das reservas cambiais e a incapacidade de financiamento do setor público resultam em crises de balanço de pagamentos, insolvência fiscal e aceleração inflacionária. A perda de bem-estar geral decorrente das crises oriundas dos ciclos populistas acaba por superar em muito o ganho transitório do que ficou conhecido nessa literatura como "distributivismo ingênuo". O aumento artificial dos salários reais provoca fortes desequilíbrios internos e externos que prejudicam a situação dos trabalhadores em termos de ganhos reais e emprego (Canitrot, 1991 [1978]).

Nos modelos tradicionais de macroeconomia do populismo na América Latina, a economia é descrita por dois setores: um primeiro baseado em bens não comercializáveis compostos por serviços e manufaturas e intensivo em trabalho e um segundo, intensivo em capital, baseado em bens comercializáveis agrícolas, especialmente dependentes da terra. A produção de manufaturas do primeiro setor depende de elevado protecionismo e é voltada para o mercado interno. Os bens agrícolas do segundo setor são produzidos principalmente para o mercado externo, como nos casos tradicionais da Argentina e Brasil.

Devido aos altos níveis de desigualdade de renda, governos populistas tentam transferir recursos para as classes mais baixas através do aumento do gasto público. A expansão monetária decorrente do financiamento dos déficits públicos reduz as taxas de juros e estimula a demanda agregada. O aquecimento da economia provoca aumentos de preços nos setores de não comercializáveis e aumento de importações de bens de consumo e capital. A prática de taxas fixas de câmbio somada aos aumentos da inflação resulta em sobrevalorizações cambiais. O ajuste é postergado, pois a política favorece inicialmente os trabalhadores, geralmente ligados ao setor de não comercializáveis. Uma desvalorização do câmbio real é vista como uma transferência de renda para as classes mais privilegiadas na medida em que beneficia a produção de bens agrícolas das oligarquias rurais para o mercado mundial (Sachs, 1991, p. 130).

Importa aqui destacar a trajetória do câmbio nesses ciclos. Ao apreciar o câmbio real, o governo aumenta salários reais de forma artificial devido à redução do preço dos bens comercializáveis. $\mathrm{O}$ aumento de salários reais tem como consequiência um acréscimo do consumo agregado, voltado para bens importados. Como a melhoria dos salários não decorre de aumentos de produtividade, o acréscimo de consumo, especialmente de bens importados, é financiado por endividamento externo. Os excessivos déficits comerciais e o agravamento das contas externas resultam numa crise no balanço de pagamentos. ${ }^{7}$

$\mathrm{Na}$ primeira fase do programa populista, as restrições macroeconômicas permitem uma expansão de gastos e endividamento externo já que, em geral,

(7) Ver Bresser-Pereira e Nakano (2003, p. 16). 
planos desse tipo são implantados após situações recessivas ou de ajustamento. A expansão da demanda no curto prazo, com decorrente aumento de emprego e salários, aumenta a credibilidade das autoridades e estimula a manutenção do programa. A economia atinge então pontos de estrangulamento. Déficits públicos, déficits externos e aumento da inflação sinalizam a gravidade do problema. $\mathrm{O}$ ajuste é postergado devido a seu alto custo social. A escassez generalizada de produtos, aceleração extrema da inflação e a defasagem cambial estimulam fugas de capital. O programa entra em colapso e uma grande desvalorização cambial segue como conseqüência do ajustamento. Na seqüência, um plano de estabilização ortodoxo impõe grandes custos sociais, com reduções consideráveis nos salários reais. As conseqüências negativas do ciclo populista tendem a se perpetuar, com redução de investimentos e emprego. Muitas vezes as desvalorizações são acompanhadas de medidas de controle cambial que acabam também por estimular o surgimento de mercados paralelos de divisas.

Muitos autores analisaram episódios de populismo econômico na América Latina. Sachs (1991) discute três ciclos entre 1970 e 1990: Chile durante os anos 1970-1973, Brasil, 1985-1987 e Peru, 1985-1987. Em todos esses períodos, podem-se observar as características acima elencadas: descontrole do orçamento, intensa apreciação cambial, crise no balanço de pagamentos e descontrole da inflação. Em todos os ciclos observa-se um crescimento acelerado do PIB num primeiro momento seguido de fortes ajustes recessivos. Salvador Allende no período 1971-1973, José Sarney entre 1985-1987 e Alan Garcia de 1985 a 1988 teriam todos, a seu modo, praticado o tipo de política econômica descrita acima. Sachs vai além e identifica no populismo econômico uma das causas fundamentais das inflações crônicas latino-americanas: "O populismo econômico ajuda a explicar o fato de que, em 1987, havia nada menos do que cinco países latinoamericanos (Argentina, Brasil, México, Nicarágua e Peru) com taxas de inflação de três dígitos" (Sachs, 1991, p. 126).

A recorrência dos ciclos populistas na América Latina chama a atenção. $\mathrm{O}$ ciclo característico do populismo se repete inúmeras vezes como tentativa de melhorar a distribuição de renda na região, "again and again, and in country after country, policymakers have embraced economic programs that rely heavily on the use of expansive fiscal and credit policies and overvalued currency to accelerate growth and redistribute income" (Dornbusch; Edwards, 1995, p. 7). Cardoso e Helwege (1991) tratam do populismo clássico de Perón na Argentina entre os anos de 1946 e 1949, além do caso chileno no período Allende. Analisam também o período dos sandinistas na Nicarágua, com destaque para a grande sobrevalorização da moeda no início dos 1980. Concluem, entretanto, que a situação da Nicarágua na década de 1980 se aproxima muito mais de um programa socialista do que de um caso de populismo econômico. Cardoso e Helwege (1991) 
e Bresser-Pereira (1991) também identificam traços de populismo no ajustamento brasileiro do início dos anos 1980 e no governo Sarney entre 1985 e 1987.

A administração do câmbio nominal foi também amplamente utilizada ao longo do século XX como instrumento de controle inflacionário. No caso das âncoras cambiais, a fixação do preço dos bens comercializáveis na moeda local através do congelamento do câmbio nominal introduz forte pressão estabilizadora no nível geral de preços. No caso das "tablitas" ou indexação de preços via administração do câmbio nominal, a prática de desvalorizações nominais menores do que o aumento de preços tem como principal função coordenar as expectativas inflacionárias. Quanto maior a penetração de bens importados no tecido econômico e, portanto, maior a presença relativa de bens comercializáveis na economia, maior a eficácia do controle da inflação através da administração do câmbio. $\mathrm{O}$ tradicional efeito colateral desse tipo de estratégia diz respeito à apreciação e, no limite, sobrevalorização do câmbio real. Admitindo-se que os processos inflacionários vêm acompanhados por inércia, um congelamento nominal do câmbio ou uma redução no ritmo de desvalorizações nominais serão usualmente acompanhados de apreciação real devido a aumentos residuais de preços. $\mathrm{O}$ efeito será tanto mais intenso quanto maior for o aumento de preços dos bens não comercializáveis não expostos à concorrência dos bens importados.

O controle da inflação via administração cambial depende quase que exclusivamente da redução de preços dos bens comercializáveis. Programas de estabilização baseados nessa estratégia terão sucesso se conseguirem reduzir os preços dos não comercializáveis a partir do controle de preços dos bens comercializáveis. Quanto maior for a inércia de preços no setor de não comercializáveis, maior a probabilidade de ocorrência de desalinhamentos cambiais e crises no balanço de pagamentos. Dependendo da intensidade da apreciação real, um ciclo de aumento de consumo nas linhas do populismo cambial poderá ser desencadeado, resultando em grandes crises externas. ${ }^{8}$

Ao discutir as diversas abordagens em relação à política cambial, Corden (2002) resume a estratégia da ancoragem cambial nos processos de estabilização ao caracterizar o "nominal anchors approach" em relação a taxas de câmbio. Nos casos de países com altos níveis de inflação, como Brasil e Argentina, por exemplo, a fixação da taxa de câmbio em relação a alguma moeda com histórico de baixa inflação é uma ferramenta poderosa para conter processos inflacionários e coordenar expectativas. A taxa de câmbio passa a ser a âncora nominal do sistema, substituindo outras âncoras como metas de inflação ou metas de agregados monetários. Nesse tipo de abordagem, a âncora cambial pode fornecer disciplina e credibilidade ao transmitir o sinal de que déficits públicos não serão monetizados e aumentos de preços e salários não serão sancionados por aumentos

(8) Ver Dornbusch, 2002 (p. 251). 
de base monetária. Corden (2002) chama a atenção para os possíveis efeitos colaterais das ancoragens cambiais na medida em que removem um importante instrumento de política econômica, o ajuste do câmbio real. As conseqüências da utilização desse tipo de estratégia em termos de recessão e desemprego podem ser bastante intensas.

Um bom exemplo de sobrevalorização cambial decorrente de programas de controle inflacionário está nos planos de estabilização do Cone Sul (Argentina, Uruguai e Chile) no final dos anos 1970. Ao fixar uma taxa de desvalorização cambial menor do que o ritmo de aumento de preços na tentativa de coordenar as expectativas inflacionárias, os planos de estabilização latino-americanos acabaram por criar fortes passivos externos que resultaram na maioria das vezes em crises de balanço de pagamentos. Nos termos de Carlos Díaz-Alejandro (1991), “contar com uma taxa de desvalorização declinante e pré-anunciada da taxa de câmbio como instrumento-chave para baixar a inflação também parece ser excessivamente arriscado. Uma inflação persistente nos preços de bens que não são objeto de comércio internacional pode levar a sobrevalorização" (p. 92).

Dentre muitos autores que trataram do assunto, Dornbusch et al. (1995) analisam três casos de significante apreciação real nos últimos vinte anos na América Latina decorrentes de planos de estabilização de preços: México 19781982, Chile 1978-1982, e México 1990-1994. No caso mexicano, ressaltam as semelhanças do que teriam sido dois grandes ciclos de apreciação resultantes em grandes crises de balanço de pagamentos em 1982 e 1994. Ao comparar o desempenho chileno com o mexicano depois da crise da dívida, dão grande ênfase à política cambial competitiva praticada pelo Chile como um dos principais fatores responsáveis pelo seu sucesso, comparado ao relativo fracasso mexicano. ${ }^{9}$

A Argentina representa um caso paradigmático de sobrevalorização cambial e crise nos anos 1990. Depois da bem sucedida implantação da caixa de conversão e do programa de estabilização no início dos 1990, o câmbio real se apreciou consideravelmente, especialmente após o fortalecimento do dólar na segunda metade dos 1990 e da desvalorização brasileira em 1999. De fato, os principais ciclos de apreciação da América Latina nos anos 1990 estão associados a 3 grandes programas de estabilização: México 1987, Brasil 1994 e Argentina 1991. A utilização da ancoragem cambial nos três planos, entre outras medidas, trouxe como conseqüência negativa apreciações cambiais que acabaram por resultar em três grandes crises externas: México em 1994, Brasil em 1999 e Argentina em 2001.

O programa de estabilização chileno iniciado no final dos anos 1970 também guarda semelhanças com esses casos. A partir de sua implantação, observa-se uma considerável apreciação cambial, que somada a outros fatores,

(9) Ver Dornbusch et al. (1995, p. 259). 
acaba por terminar numa crise em 1982. Os quatro ciclos foram muito parecidos com os episódios de populismo cambial discutidos acima. Inicialmente observouse crescimento nos quatro países. Os salários reais aumentaram, o consumo aumentou, o endividamento externo aumentou e finalmente o balanço de pagamentos entrou em colapso, seguido de forte depreciação cambial. Todos os ciclos foram acompanhados de crescente apreciação cambial até o momento da crise. $^{10}$

Todas as crises dos anos 1990 na América Latina estão associadas a problemas de apreciação cambial. Palma (2003), por exemplo, identifica três rotas para crises financeiras em países em desenvolvimento desde a crise da dívida de 1982. Na primeira, representada principalmente pelas experiências de liberalização financeira e estabilização chilena 1975-1982, mexicana 1987-1994 e argentina 1990-2000, houve grande aumento de crédito ao setor privado, sobrevalorização cambial, bolhas nos mercados de ativos e um "boom" de consumo de importados. $\mathrm{Na}$ segunda rota seguida pelo Brasil entre 1994-1998, a tentativa de se evitar os erros contidos na rota 1 acabou por criar um novo caminho para a crise. A esterilização dos fluxos de capital somada a prática de altas taxas de juros para evitar um "boom" de consumo e a dificuldade de controle de gastos públicos acabou por colocar a dinâmica da dívida pública em trajetória insustentável. $\mathrm{Na}$ terceira rota, representada pelo caso da Coréia do Sul entre 1988-1996, a queda no preço de componentes eletrônicos no mercado internacional devido à entrada da forte concorrência de Taiwan levou a queda nas margens de lucro das empresas coreanas que passaram a buscar financiamento no endividamento externo.

As sobrevalorizações resultantes dos programas de estabilização inflacionária em muito se assemelham aos episódios de populismo econômico. A fixação da taxa de câmbio nominal ou a redução do ritmo de desvalorizações associadas à inércia nos preços dos bens não comercializáveis acabam gerando resultados parecidos aos dos programas populistas. Ambos produziram excessivos aumentos de preços dos bens não comercializáveis em relação aos comercializáveis resultando em desalinhamento do câmbio real. A queda das exportações e aumento das importações provocou aumento do endividamento externo e, no limite, crises.

\section{Subvalorizações no Sudeste Asiático}

As oito principais economias asiáticas, Japão, Coréia do Sul, Taiwan, Cingapura, Hong Kong, Indonésia, Malásia e Tailândia cresceram em termos per capita a uma taxa de 5,5\% ao ano no período 1965-1990. Nos anos 1990, mesmo com a crise de 1997, a taxa média de crescimento per capita desses países, com a

(10) Para uma análise resumida dos casos de Chile, México e Brasil, ver Dornbusch (2002, p. 252-262). 
exceção do Japão, se manteve alta, acima dos níveis latino-americanos. Mais recentemente, a China vem apresentando níveis e padrão de crescimento semelhantes ao modelo asiático. A controvérsia sobre as causas do sucesso dessa experiência, especialmente para o primeiro grupo de economias, persiste até hoje. O debate gira principalmente em torno do papel da intervenção do estado nesse processo de desenvolvimento. O grupo ligado ao Banco Mundial ressalta a importância de "market friendly polices" como estratégia responsável pelos bons resultados dessas economias e assinala, de modo algo contraditório, o problema do "crony capitalism" como uma das principais causas da crise asiática de 1997. Os críticos, dentre os quais se destacam Amsden (1989), Wade (1990), Rodrik (1994) e Chang (2003), ressaltam a importância da intervenção estatal bem conduzida como fator responsável pelo sucesso asiático e localizam na liberalização financeira dos anos 1990 uma das principais causas da crise de 1997.

Um dos pontos de convergência nesse debate parece se encontrar no reconhecimento da importância da estabilidade macroeconômica para o crescimento, especialmente no que diz respeito à manutenção da competitividade da taxa de câmbio. Rodrik (1994), por exemplo, critica o que chama de postura do fetichismo exportador adotada pelo Banco Mundial no relatório de 1993, mas reconhece a importância da prática de câmbios competitivos no processo de desenvolvimento asiático (Rodrik, 1994, p. 37). Williamson (1999) destaca a superioridade dos asiáticos ao analisar a questão da condução da política cambial em países em desenvolvimento. Nas palavras do autor,

the first point that has to be acknowledged is that East Asian countries have for some years managed their exchange rates far better than other groups of developing countries. They have not crucified their economies by misconceived attempts to use the exchange rate as a nominal anchor. They have not allowed their currencies to become so overvalued, either by keeping their exchanges rates fixed in the face of differential inflation or by allowing them to float up too much, as to jeopardize export growth (Williamson, 1999, p. 331).

O Banco Mundial também é explícito a esse respeito. No seu famoso relatório de 1993, destaca a importância das políticas cambiais nesse processo. A prática de taxas de câmbio real relativamente desvalorizadas teria estimulado a formação de um dinâmico setor de bens comercializáveis que contribuiu para a acumulação de capital e inovações tecnológicas nesses países. Esse teria sido um dos pilares do modelo de "export-led growth" da região. Muitos governos asiáticos usaram a política cambial para atenuar os efeitos negativos de liberalizações comerciais para produtores de bens substitutos de importação. Alguns foram além, utilizando deliberadamente a relativa desvalorização do câmbio real como forma de estímulo ao setor exportador. Nesses casos, a política cambial teria se integrado com as políticas fiscal e monetária numa estratégia geral de "export-led growth". "Taiwan, China, is the most notable example of this, but 
Korea and Indonesia also deliberately undervalued their currencies to boost exports" (World Bank, 1993, p. 125).

O relatório destaca três casos de forte intervenção cambial com vistas à manutenção da competitividade externa. Os grandes superávits em conta corrente de Taiwan no período de 1984 a 1987 (com média de 16\% do PIB e um pico de $20 \%$ em 1986) resultaram de esforços do governo de Taiwan para manter a moeda desvalorizada. Uma apreciação da moeda anularia rapidamente esse resultado de conta corrente, prejudicando a estratégia de crescimento liderado pelas exportações. A Coréia do Sul também interveio fortemente no meio dos 80 para evitar uma apreciação expressiva do won, acumulando reservas e mantendo a competitividade externa. A desvalorização da rúpia na Indonésia em 1978 foi claramente uma medida de proteção já que seu balanço de pagamentos não apresentava problemas nesse ano. A deterioração de suas contas externas em 1982 teve um impacto moderado no seu desempenho econômico devido às medidas tomadas no final dos anos $1970 .{ }^{11}$

Sobre os asiáticos e suas estratégias de desenvolvimento, em contraste com países da África e especialmente da América Latina, o Banco chama a atenção para o que foi um dos principais motores do aumento de produtividade dos primeiros: promoção deliberada de manufaturas para exportação. Destaca que depois de passar por uma fase de substituição de importações, esses países mudaram para a estratégia de industrialização com promoção de exportações (EPI), especialmente pela necessidade de aquisição de divisas. Na busca de mercados externos para a produção doméstica, esse grupo de países, Hong Kong, Cingapura, Coréia do Sul, Taiwan, Indonésia, Malásia, e Tailândia, teria adotado uma série de estímulos para as exportações.

Outros estudos também destacam uma administração pró-competitividade da taxa de câmbio na Ásia. Dornbusch e Park (1999) ressaltam alguns casos de países asiáticos que perseguiram metas de câmbio real para favorecer exportações nos anos 1980 e 1990. No caso da Malásia, especialmente depois da sobrevalorização do início dos anos 1980, maior atenção passou a ser dada para a trajetória do câmbio real. "Bank Negara manages the ringgit to support the nation's export competitiveness and maintain monetary stability. Occasionally it administers exchange controls on behalf of the Malaysian government" (Dornbusch; Park, 1999, p. 28). No caso de Cingapura, por exemplo, a autoridade monetária além de zelar pelo controle de preços "is also watchful of the impact of the exchange rate on the country export competitiveness. This targeting renders interest rate policy subordinate to exchange rate policy" (p. 27).

$\mathrm{Na}$ Coréia do Sul, a ação do Banco Central é semelhante. Segundo os autores, o BC coreano interviria com frequiência no mercado de câmbio para

(11) Ver também, a respeito, Belluzzo e Tavares, 2005, p. 229. 
estabilizar o won e manter a competitividade das exportações sul coreanas no mercado internacional. Ao analisar vinte anos de política econômica na Coréia do Sul, Rhee e Song (1999, p. 80) também destacam a preocupação das autoridades monetárias coreanas na administração de um nível competitivo do won. Ao longo dos anos 1980, o país passou por um breve ciclo de apreciação por conta do bom desempenho das exportações, especialmente no meio da década. A intervenção do Banco Central foi assimétrica no sentido de privilegiar as exportações. ${ }^{12}$ No início dos 1990, as autoridades monetárias tiveram grande dificuldade para evitar a apreciação do won devido aos intensos fluxos de capital. A estratégia de compra de reservas foi permanente e no ano de 1993 o Banco Central comprou mais de 1,8 bilhão de dólares em apenas um dia. Num estudo sobre quatro países asiáticos, Barrell et al. (1999) identificam práticas de defesa de competitividade via política cambial na Coréia do Sul, Taiwan e Tailândia, mas reduzem sua importância em Cingapura (Barrell et al., 1999, p. 271).

É importante notar, entretanto, que alguma apreciação real passou a ser observada nessa região, especialmente no período 1995-1997 quando o dólar começa a se apreciar mais fortemente em relação ao yen. Coréia do Sul, Filipinas, Malásia e Tailândia estão entre os países que teriam passado por relativa apreciação com possíveis impactos na crise de 1997. ${ }^{13}$ Como destaca Lim (2004), ao permitir a apreciação de suas moedas, estes países estavam agindo em sentido contrário a sua estratégia de sucesso. Além da questão dos excessivos fluxos de capital de curto prazo e regulação e supervisão bancária apontada por muitos como uma das principais causas da crise asiática, o autor destaca o problema dos déficits em conta corrente e sobrevalorização cambial. "This last was what made the East Asian countries eventually 'un-East Asian` since the earlier East Asian stereotype was a high saver and a high earner of foreign exchange" (Lim, 2004, p. 67).

A China representa atualmente um bom exemplo da estratégia de política cambial perseguida pelos asiáticos. No seu relatório de 1993, o Banco Mundial também ressalta a importância de uma política de desvalorização cambial deliberada do governo chinês presente na estratégia de promoção de exportações e crescimento desde o final dos anos $1970 .{ }^{14}$ A estratégia chinesa, que segue os passos da Coréia do Sul e do Japão, de manter um câmbio permanentemente desvalorizado tem levado a um crescimento sustentado de seu estoque de capital e produto. Um câmbio competitivo estimula exportações, promove investimento e, portanto, favorece a acumulação de um estoque de bens de capital de alto padrão voltado para a produção de bens comercializáveis. ${ }^{15}$

(12) Cf. Rhee e Song (1999, p. 80), ver também Medeiros (1997, p. 302).

(13) Ver Montiel (2003) e Lim (2004).

(14) Cf. World Bank (1993, p. 59); ver também Medeiros (1997, p. 303).

(15) Para uma análise do caso japonês, ver Eichengreen e Hatase (2005). 
O livre funcionamento do mercado cambial, associado à liberdade de fluxos de capital, provocaria um ajustamento dos excessivos superávits na conta comercial e na conta corrente da China através de uma apreciação cambial. Um câmbio mais apreciado estimularia o consumo de bens importados, revertendo o saldo da balança comercial e desestimularia o investimento na produção de bens comercializáveis a partir de uma mudança de preços relativos. O ponto interessante nesse argumento é que a intervenção do governo do mercado cambial através da aquisição maciça de reservas cria uma distorção favorável ao crescimento. Não está claro se uma estratégia de câmbio flutuante, com decorrente apreciação, seria então melhor para a China hoje. ${ }^{16}$

No arranjo atual da economia global, Dooley et al. (2003) identificam três regiões distintas em termos de estratégia de política econômica. O centro do sistema é formado pela economia americana que não tem grandes preocupações com o comportamento de sua taxa de câmbio já que são emissores da moeda reserva do sistema internacional. Os déficits em conta corrente americanos decorrentes do excesso de absorção sobre a produção das empresas, famílias e governo são financiados com poupança externa dos países que se encontram na chamada "current account region", composta basicamente por países do Leste e Sudeste Asiático. Estes têm como estratégia exportar poupança para a economia americana através de uma produção maior do que suas necessidades de absorção, crescem, portanto, com despoupança externa. As "capital account regions", compostas principalmente pela Europa e América Latina, optaram por se integrar financeira e não comercialmente ao sistema global. Nessa estratégia, a manutenção de um superávit na balança comercial e nas contas correntes não é prioritária.

Como o superávit comercial e em contas correntes é uma meta da "current account region", sua estratégia básica é praticar um câmbio real relativamente desvalorizado com fortes intervenções no mercado cambial. Em caso de necessidade podem também utilizar controles de capital, como na China, que auxiliem nessa tarefa. A maior dificuldade dessa estratégia é evitar pressões especulativas no sentido de apreciação da moeda. $\mathrm{O}$ acesso a fundos é dificultado a agentes privados e o governo controla o mercado de câmbio através da autoridade monetária que compra reservas e as aplica em títulos americanos. No caso dos países das "capital account regions", os eventuais superávits em conta corrente se transformam em apreciação cambial que reduz ou anula o estímulo exportador. Nesse modelo, privilegia-se o retorno das aplicações dos agentes privados no sistema internacional. Esses países operam sem controles de capital e com câmbio flutuante.

Em termos históricos, esse arranjo reproduz o esquema da economia mundial no pós-guerra. No arcabouço original de Bretton Woods, o centro do

(16) Ver Eichengreen (2004). 
sistema eram os Estados Unidos e a periferia a Europa Ocidental e o Japão. A estratégia de reconstrução dessas economias seguia o padrão observado hoje. Através de um crescimento liderado pelo setor exportador, os países destruídos na guerra reconstruíram seu estoque de capital. Praticavam taxas de câmbio fixas e controles de capital que contribuíam nessa direção, sendo importante notar que à época os controles de capital eram obrigatórios e não opcionais. Com o desenvolvimento econômico surgiu naturalmente um lobby contrário aos controles de capital que seriam abolidos no início dos anos 1970. O desenvolvimento industrial levou a um desenvolvimento financeiro que no final do processo desmontou o arranjo de Bretton Woods.

Como destacam Dooley et al. (2003), atualmente a periferia foi recarregada e assistimos a um processo parecido com o que se observou entre os anos 1950 e 1970. Uma das questões que ainda não está clara dentro desse contexto é a sustentabilidade dos déficits americanos. A visão padrão contida nas idéias do "consenso de Washington" teme um ajustamento abrupto desse arranjo que traria conseqüências negativas para a economia americana e para o resto do sistema mundial. Na visão do sistema de Bretton Woods revivido, esse ajustamento seria gradual e ainda poderia levar muito tempo. Como destacam, o arranjo é funcional para o desenvolvimento da região asiática que vem crescendo de forma sustentada e incorporando mão de obra ociosa ao seu mercado de trabalho nos últimos anos. Somente a China contaria ainda com 200 milhões de trabalhadores que poderiam entrar no mercado de trabalho. Essa a estratégia de desenvolvimento da "current account region" que é plenamente compatível com os objetivos americanos atuais de crescimento com endividamento. Dentro dessa lógica, a apreciação do dólar frente às moedas asiáticas significa acréscimo do componente consumo do gasto americano e redução de suas exportações como espelho do balanço de pagamentos asiático ${ }^{17}$.

\section{Evolução da taxa de câmbio real na Ásia e América Latina}

O Gráfico 1 apresenta o comportamento da taxa de câmbio real em relação ao dólar americano (calculada a partir dos dados de Easterly, 2001) para alguns dos principais ciclos de apreciação da América Latina no período 1970-2000. Destacam-se os casos de populismo elencados por Sachs (1991), os episódios de liberalização financeira e estabilização analisados por Palma (2003) e os casos de apreciação ressaltados por Dornbusch et al. (1995). Na comparação entre as moedas asiáticas e latino-americanas nos anos 1990, percebe-se que os ciclos de apreciação dos primeiros foram muito maiores. Coréia do Sul, Tailândia e Malásia apresentaram também alguma apreciação em relação ao dólar nos anos de 1995,

(17) Ver também Belluzzo (2005).

Economia e Sociedade, Campinas, v. 16, n. 1 (29), p. 65-91, abr. 2007. 
1996 e 1997, mas ainda assim menores do que nos casos latino-americanos. Alguns autores argumentam que a apreciação em alguns dos países asiáticos foi um dos fatores responsáveis pela crise de $1997 .^{18}$

Gráfico 1

Ciclos de apreciação na América Latina e Sudeste Asiático

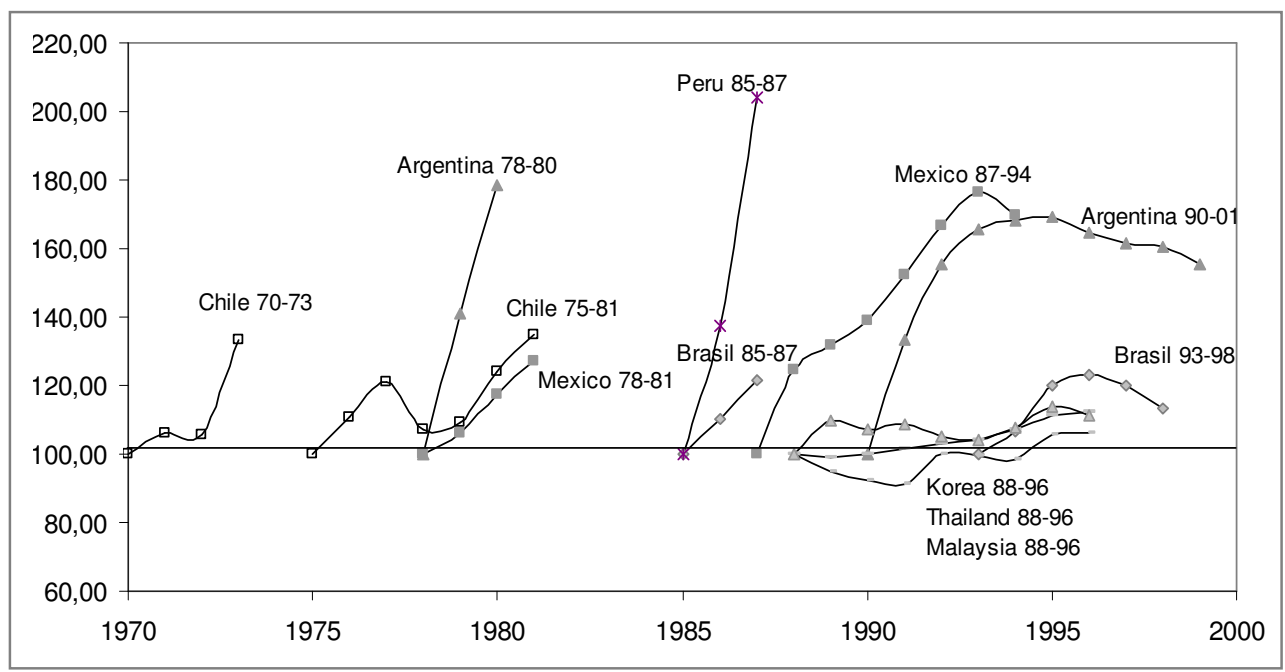

Fonte: Elaboração do autor a partir de dados de Easterly (2001).

A partir dos dados de câmbio real de Easterly (2001) pode-se construir uma rotina simples, capaz de detectar ciclos de apreciação na Ásia e América Latina no período 1970-1999. Definindo-se um ciclo de apreciação cambial como uma seqüência de $\mathrm{n}$ anos com um câmbio real médio superior a $\mathrm{x} \%$ em relação a um ano-base, podem-se calcular ciclos de apreciação a partir da divisão da média de três anos subseqüentes em relação a um dado ano-base. Analisando-se a ocorrência desses rápidos ciclos de apreciação cambial na Ásia e América Latina, encontra-se uma grande diferença. Para três anos com apreciação média de $30 \%$ em relação ao ano-base, encontram-se 16 anos base no que parecem ser nove ciclos de apreciação para América Latina e 4 anos base que parecem constituir dois ciclos para a Ásia numa amostra de 10 países para cada continente. Se se estende em um ano o ciclo, ou seja, quatro anos de câmbio real médio $30 \%$ acima do ano-base, encontram-se 24 anos base e 11 ciclos para a América Latina e cinco anos base com ainda dois ciclos para a Ásia. Relaxando-se as restrições do ciclo de apreciação para um câmbio real médio superior em três anos a $15 \%$ do anobase encontram-se 59 casos para a América Latina e 25 para a Ásia.

Com o intuito de avaliar os efeitos do nível do câmbio real e do protecionismo em trajetórias de crescimento, Dollar (1992) constrói um índice de

(18) Ver Lim (2004), por exemplo. 
distorção cambial ou "outward orientation" para 95 países no período 1976-1985. Baseando-se nos dados de Summers e Heston, compara níveis de preços relativos entre esses países e os Estados Unidos. Aplica, ademais, um ajuste de renda per capita para corrigir o efeito Harrod-Balassa-Samuelson que vincula aumentos do nível de renda per capita a apreciações cambiais. No índice de "outward orientation" calculado pelo autor, um alto nível de preços relativos significa um câmbio real apreciado e maior protecionismo tarifário e um baixo nível de preços significa menor protecionismo e um câmbio relativamente depreciado. Alguns autores, como Rodrik (1994), por exemplo, criticam o trabalho de Dollar (1992) argumentado que seu índice não é adequado para medir graus de protecionismo, sendo muito mais apropriado para medidas de apreciação cambial. Seguindo essa interpretação, os resultados de Dollar apontam para uma relativa desvalorização nas moedas dos países asiáticos quando comparados a América Latina e África. Para o período 1976-1985, o autor encontra uma apreciação relativa de $33 \%$ das moedas latino-americanas e de $86 \%$ das africanas em relação às asiáticas. ${ }^{19}$

Ao medir posições de câmbios reais para os anos de 1993 e 1998 a partir de desvios de PPP para 61 países desenvolvidos e em desenvolvimento, Benaroya e Janci (1999) também encontram evidências de que moedas asiáticas estavam em posições relativamente depreciadas em relação ao dólar americano em linha com Dollar (1992). Li Lian Ong (1997) trabalha com o índice Big Mac para medir posições cambiais de 34 países. Calcula subvalorizações e sobrevalorizações de moedas baseando-se no preço do Big Mac em dólares em cada país, "the perfect universal commodity". Encontra relativa desvalorização no sudeste da Ásia, especialmente nos países do ASEAN: Malásia, Cingapura, Tailândia, Filipinas e Indonésia (Ong, 1998, p. 89).

Além das tradicionais comparações baseadas em preços PPP (Big Mac PPP index), constrói um índice para corrigir o que chama de "productivity bias" resultante da hipótese Harrod-Balassa-Samuelson. Desconta das variações cambiais um componente de aumento de produtividade que usa como "proxy" o PIB per capita real de cada país. Seguindo esse cálculo, encontra uma relativa subvalorização das moedas asiáticas, novamente com destaque para os países do ASEAN. Ong (1997) mostra que para a média do período 1986-1994 o ringgit da Malásia, o dólar de Cingapura e o baht da Tailândia estavam subvalorizados respectivamente em 53\%, 26\% e 19\% em relação ao dólar americano. Para o ano de 1997 o índice apresenta alguma valorização, indo de encontro à interpretação de autores de que uma sobrevalorização das moedas asiáticas teria contribuído para a crise de 1997.

Em estudo sobre o tema, Rajapatirana e Athukorala (2003) analisam o impacto dos fluxos de capital nas taxas de câmbio real de 8 países da Ásia e

(19) Cf. Dollar (1992, p. 539); para uma análise de apreciações na África, ver Ghura e Greenes (1993) e Shatz e Tarr (2000).

Economia e Sociedade, Campinas, v. 16, n. 1 (29), p. 65-91, abr. 2007. 
América Latina entre 1985 e 2000. Mostram que a apreciação das moedas asiáticas em relação a uma cesta de moedas de parceiros comerciais foi menor do que as latino-americanas, especialmente nos casos de China e Índia (para uma análise de "real exchange rate targeting" na Índia, ver Patel 1997). As apreciações latino-americanas situaram-se na faixa de $14,7 \%$ e $43,5 \%$, enquanto para as moedas asiáticas esse número variou de $2,3 \%$ a $11,2 \%$ atingido pelas Filipinas (Rajapatirana; Athukorala, 2003, p. 625). Segundo cálculos dos autores, para cada 1 ponto percentual de acréscimo de fluxos de capital no período, com a exceção de investimento direto externo, observa-se uma apreciação de 1,7 pontos percentuais nas moedas de países da América Latina e 0,56 pontos percentuais para a média de toda a amostra. Curiosamente, os autores encontram uma correlação negativa entre investimento direto estrangeiro (IDE) e o nível do câmbio. Quanto maior o IDE, mais depreciado o câmbio real. Esse resultado poderia ser explicado pelo o que os autores chamam de "tradable bias" presente no IDE, ou seja, a tendência destes investimentos se concentrarem primordialmente no setor de comercializáveis, que necessita de uma taxa de câmbio mais competitiva.

Ainda nesse registro, Sachs et al. (1996) analisam as causas da crise mexicana de 1995 e seus efeitos em 20 países emergentes. Elencam três fatores como causas principais para a explicação de crises: sobrevalorização cambial, baixo nível de reservas cambiais e falta de solidez no sistema financeiro. Segundo os autores, economias que apresentavam essas três características sofreram com muito maior intensidade o efeito tequila: Argentina e Filipinas. Ao comparar a posição de câmbios reais em relação à cesta de moedas de parceiros comerciais no período 1990-1994 com base em 1986-1989, encontram novamente câmbios relativamente apreciados na América Latina em comparação com o sudeste da Ásia, com a exceção de Chile e Colômbia. Na Ásia, as Filipinas são a exceção, " $a$ striking fact in the data is that the Latin American countries experienced sharper real appreciations than did East Asian economies" (Sachs et al., 1996, p. 4).

Comparando-se as médias da posição de câmbios reais para 10 economias de cada região a partir dos dados de Easterly (2001), complementados com o cálculo de um índice para o Brasil no período 1970-1985, pode-se analisar a tendência das posições das moedas asiáticas e latino-americanas para um longo período de 30 anos. A média dos índices para os 10 países latino-americanos no período 1970-1999 atinge 104,5, ou seja 4,5\% acima do equilíbrio de PPP (representado pelo eixo horizontal no Gráfico 2) em relação à moeda americana enquanto para as moedas asiáticas a média dos índices de câmbio real atinge 82,7, ou seja 17,3 pontos percentuais abaixo do equilíbrio de PPP. Os dados abaixo mostram que os níveis de câmbio real em termos de dólar na América Latina parecem estar relativamente apreciados em relação aos asiáticos no período 19701999. Argentina, Peru, Brasil, Uruguai e México apresentam uma tendência de depreciação nos 1980 e apreciação nos 1990. Bolívia e Paraguai apresentam 
apreciação nos 1980 e depreciação nos 1990. Chile, Venezuela e Colômbia apresentam uma tendência persistente à depreciação nos últimos anos. Na Ásia, Taiwan, Coréia do Sul e Cingapura apresentam uma tendência de apreciação nos últimos anos. Todos outros países da amostra, Índia, Tailândia, Malásia, Filipinas, Indonésia, Sri Lanka e Paquistão apresentam uma tendência recorrente à depreciação.

Gráfico 2

Nível de câmbio real - Ásia

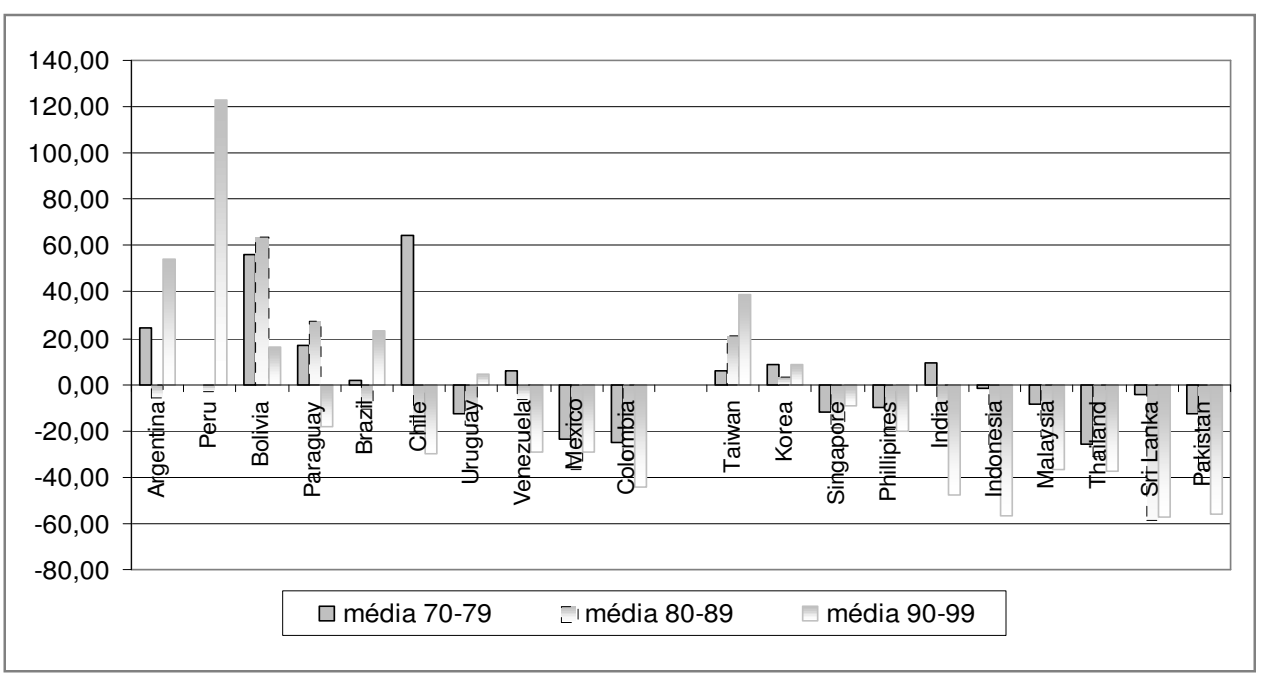

Fonte: Elaboração do autor a partir de dados de Easterly (2001).

Importante notar que as apreciações na América Latina estão muito mais ligadas a ciclos populistas e programas de estabilização do que a um desempenho exemplar do setor exportador. As apreciações de países como Taiwan, Coréia do Sul e Cingapura estão associadas ao sucesso exportador e recorrentes períodos de superávits em contas correntes que acabam por pressionar o câmbio. As apreciações asiáticas parecem muito mais sadias do que as latino-americanas já que decorrem de bons desempenhos no comércio externo e aumentos de produtividade. Para ficar em três exemplos, as rendas reais per capita de Taiwan, Coréia do Sul e Cingapura passaram de uma média de $10 \%$ da renda norteamericana no final dos anos 1960 para mais de 60\% no final dos anos 1990, sendo que Cingapura atingiu mais de $80 \%$ da renda per capita dos Estados Unidos em 1999. Em 1995 o superávit em transações correntes de Cingapura atingiu 14\% do PIB e foi quase que totalmente utilizado para comprar reservas que eram à época da ordem de U\$ 67 bilhões para uma população de 3 milhões de habitantes.

O Gráfico 3 mostra uma comparação entre distorções cambiais entre países, medidas como desvios do câmbio real em termos de dólar em relação à regra Harrod-Balassa-Samuelson; quanto maior a renda per capita de um 
determinado país, mais apreciado deve estar seu câmbio em relação aos seus parceiros comerciais (ver Dollar, 1992). A partir desse índice de correção cambial $R E R^{*}$, a diferença entre os dois grupos fica ainda mais clara.

Gráfico 3

Nível de distorção do câmbio real - Ásia e América Latina

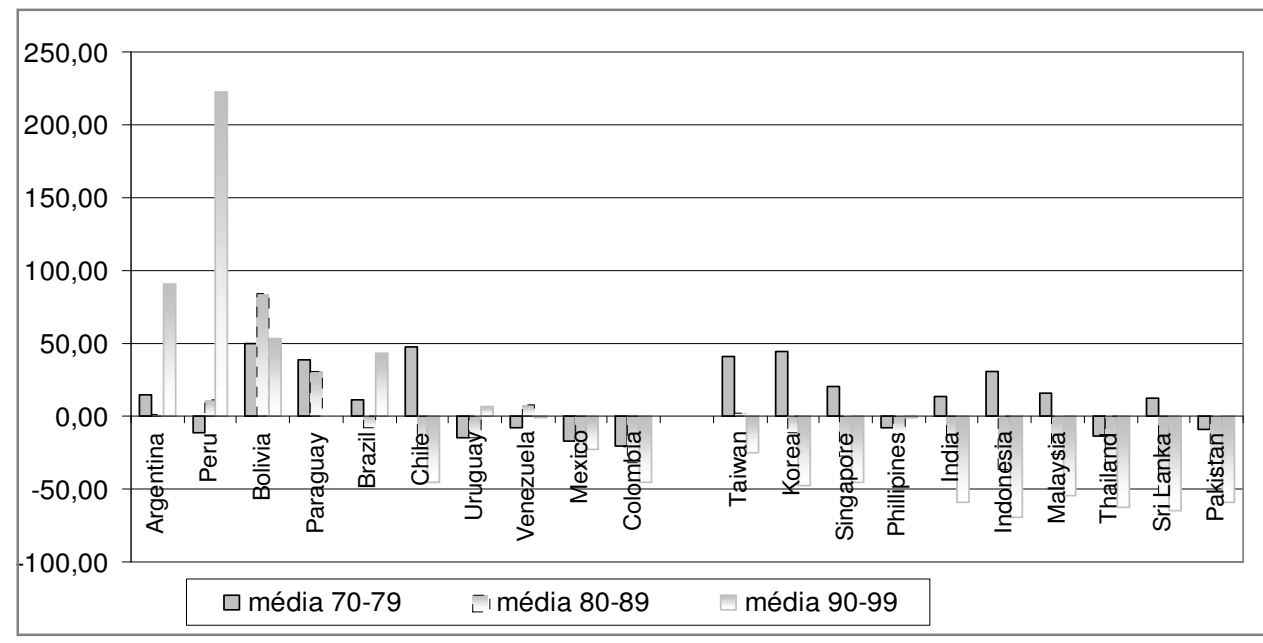

Fonte: Elaboração do autor a partir de dados de Easterly (2001).

A média dos índices de distorção no período 1970-1999 atinge 79,67 para os asiáticos e 113,79 para os latino-americanos. No grupo dos asiáticos, com a exceção das Filipinas, todos os países apresentam uma clara tendência de desvalorização nos anos 1980 e 1990. Para os latino-americanos, o padrão do índice segue o comportamento do câmbio real apresentado acima. Peru e Uruguai apresentam uma tendência de apreciação contínua. Argentina, Brasil e México apresentam uma tendência de depreciação nos 1980 e apreciação nos 1990. Bolívia e Venezuela apresentam apreciação nos 1980 e depreciação nos 1990. Paraguai, Colômbia e Chile apresentam uma tendência persistente à depreciação nos últimos anos.

Utilizando-se os dados de Easterly (2001) para uma simples regressão em "cross-section" com 58 países em desenvolvimento com "dummies" para Ásia, África, América Latina e Europa, o nível de câmbio real $R E R$ apresenta também grandes diferenças regionais. ${ }^{20}$ As "dummies" de África e América Latina são significantes a 5\% e apresentam o sinal esperado. No período 1960-1999, países localizados nestas duas regiões apresentaram câmbios reais mais valorizados do que na Ásia. A tabela abaixo mostra que, na média, países latino-americanos e africanos apresentaram, respectivamente, níveis de câmbios reais mais apreciados

(20) Ver Gala e Lucinda (2006) para uma discussão detalhada acerca da construção destas séries. 
em 27 e 38 pontos percentuais quando comparados a países asiáticos. Essa simples regressão representa mais evidências da discussão apresentada até então.

Tabela 1

\begin{tabular}{l|c}
\hline Variável dependente: Ln Câmbio Real & M.Q.O. \\
\hline África & $0.3815^{* * *}$ \\
\hline & $(3.5325)$ \\
\hline América Latina & $0.2739^{*}$ \\
\hline & $(2.4614)$ \\
\hline Europa & 0.1299 \\
\hline Constante & $(0.6461)$ \\
\hline & $4.4729 * * *$ \\
\hline N-Obs & $(52.9745)$ \\
\hline R-sq & 58 \\
\hline$*$ p $<0.05, * * \mathrm{p}<0.01, * * * \mathrm{p}<0.001$ & 0.195 \\
\hline Fonte: Elaboração do autor. & \\
\hline
\end{tabular}

Conclusões mais robustas em relação às regressões dependeriam, obviamente, de futuras pesquisas empíricas mais detalhadas sobre os diversos determinantes do nível do câmbio real nessas regiões.

\section{Dois padrões}

Ao analisar o impacto da crise da dívida do início dos anos 1980 na América Latina e Ásia, Sachs (1985) conclui que o ajuste superior dos últimos se deveu primordialmente ao manejo da política cambial e ao regime de comércio de suas economias. Com a exceção das Filipinas, nenhum país do Leste ou Sudeste Asiático passou por "default" da dívida externa, situação bastante distinta da latino-americana. Sachs argumenta que essas duas regiões guardavam três características comuns e uma distinta que seria responsável pelo seu sucesso na transição da crise da dívida. Em termos de endividamento externo, os asiáticos haviam praticamente contraído uma dívida equivalente à latino-americana. A Indonésia, por exemplo, exibia um coeficiente de dívida externa sobre PIB de $28 \%$ em 1980 e a Coréia do Sul de 27,6\% em 1981, ambos maiores do que o índice do Brasil de 26,1\% para o mesmo ano. Com relação ao choque nos termos de troca, a situação não foi diferente. Sachs argumenta que alguns países asiáticos sofreram uma deterioração ainda maior do que países da América Latina. Por fim, quanto à questão de tamanhos e formas de atuação do estado nas duas regiões, destaca a semelhança do grau de intervenção dos governos no processo de desenvolvimento de ambas.

A grande diferença entre as duas regiões estaria no regime de comércio e na administração cambial. Enquanto a América Latina se concentrou num 
processo de substituição de importações voltado para o mercado interno com forte viés a apreciações cambiais, os países asiáticos perseguiram um programa de estímulo às exportações, com práticas constantes de câmbio reais competitivos. A explicação para a superioridade do ajuste asiático em relação à crise da dívida estaria, portanto, na existência de um amplo e dinâmico setor de bens comercializáveis, capaz de gerar os recursos necessários para pagar a dívida externa. A diferença entre essas duas regiões aparece claramente na comparação da razão exportações sobre dívida externa no início dos anos 1980. Indonésia, Coréia do Sul, Malásia e Tailândia apresentavam uma média ponderada de 0,821 em 1981 contra uma média de 2,715 para Argentina, Brasil, Chile, México, Peru e Venezuela no mesmo ano. Sachs $(1985$, p. 541) identifica ainda uma relativa apreciação das moedas latino-americanas em relação às asiáticas para o período 1979-81 comparado a 1976-1978, com a exceção de Brasil e Peru.

Estendendo a análise de Sachs (1985), a história aqui apresentada parece se resumir a uma tendência recorrente de ciclos de sobrevalorização na América Latina e subvalorização na Ásia, especialmente após o final dos anos 1970. Enquanto os primeiros passaram por vários ciclos de sobrevalorização cambial, com o já conhecido populismo econômico dos anos 1970 e 1980 e com os planos de estabilização dos anos 1990, os países asiáticos concentraram-se na sua estratégia de "export-led growth" com estímulo permanente ao setor exportador, evitando fortes apreciações cambiais. Ao perseguir o controle fiscal e promoção de exportações, os asiáticos evitaram muitos dos problemas latino-americanos. Enquanto os primeiros usaram o câmbio como instrumento de populismo econômico e ferramenta de estabilização, os segundos parecem ter usado o câmbio como estímulo ao setor exportador, mantendo-se fiéis a sua estratégia de desenvolvimento. Nesse sentido, a estratégia de industrialização com promoção de exportações (EPI) do Leste e Sudeste Asiático provou-se muito mais eficaz do que a estratégia de substituição de importações latino-americana (ISI).

As evidências aqui apresentadas apontam para uma recorrente subvalorização das moedas asiáticas quando comparadas às latino-americanas, especialmente ao se levar em consideração alguma medida de distorção cambial que considere variações de produtividade. Esses resultados tendem a comprovar a hipótese levantada no início do trabalho e estão em linha com a literatura empírica que ressalta a importância de câmbios competitivos como uma das explicações para o relativo sucesso dos países do Leste e Sudeste Asiático nos últimos 30 anos, notadamente quando comparado ao desempenho decepcionante dos latinoamericanos e africanos. Podem-se observar, obviamente, variações dessa estratégia dentro de cada região. Na América Latina, a mais notável exceção é a economia chilena que parece ter mudado para um padrão asiático de administração cambial em meados dos 1980. Na Ásia, a exceção fica por conta das Filipinas, o 
mais latino-americano dos países asiáticos. A guisa de conclusão, parece razoável propor que existe um padrão de condução de política cambial para cada uma dessas regiões nesses últimos trinta anos que possivelmente contribuiu para o seu desempenho de longo prazo.

\section{Referências bibliográficas}

ACEMOGLU, D.; SIMON, J.; JAMES R. Institutional causes, macroeconomic symptoms: volatility, crisis and growth. Cambridge MA: MIT, 2002.

AMSDEN, A. H. Asia's next giant, South Korea and late industrialization. Oxford: Oxford University Press, 1989.

BALASSA, B. The purchasing power parity doctrine: a reappraisal. Journal of Political Economy, p. 584-596, Dec. 1964.

BARREL, R.; ANDERTON, B.; LANSBURRY, M.; SEFTON, J. FEERs for the NICs: exchange rate policies and development strategies in Taiwan, South Korea, Singapore and Thailand. In: COLLIGNON, Stefan; PISANI-FERRY, Jean; PARK, Yung Chul (Ed.). Exchange rate policies in emerging Asian countries. New York: Routledge, 1999.

BENAROYA, F.; JANCI, D. Measuring exchange rates misalignment with purchasing power parity estimates. In: COLLIGNON, Stefan; PISANI-FERRY, Jean; PARK, Yung Chul (Ed.). Exchange rate policies in emerging Asian countries. New York: Routledge, 1999.

BELLUZZO, L. G. O dólar e os desequilíbrios globais. Revista de Economia Política, v. 25, n. 3(99), p. 224-232, jul. 2005.

; TAVARES, M. C. A mundialização do capital e a expansão do poder americano. In: FIORI, José Luis (Org.). O poder americano. Petrópolis, RJ: Vozes, 2005.

BRESSER-PEREIRA, L. C. Populismo e política econômica no Brasil. In:

(Org.). Populismo econômico: ortodoxia, desenvolvimentismo e populismo na América Latina. São Paulo: Nobel, 1991.

2001.

A fragilidade que nasce da dependência da poupança externa. Valor 1000, set.

- Financiamento para o subdesenvolvimento: o Brasil e o Segundo Consenso de Washington. In: CASTRO, Ana Célia (Org.). Desenvolvimento em debate: painéis do desenvolvimento brasileiro I, v. 2. Rio de Janeiro: Mauad/BNDES, 2002. p. 359-398.

Brazil's quasi-stagnation and the growth cum foreign savings strategy. International Journal of Political Economy, v. 32, n. 4, p. 76-102, 2004.

- Exchange rate, fix, float or manage it? Preface to Mathias Vernengo, ed.

Financial integration or dollarization: no panacea. Cheltenham: Edward Elgar, 2006.

; NAKANO, Y. Crescimento com poupança externa? Revista de Economia Política, v. 22, n. 2, abr. 2003. 
CANITROT, A. A experiência populista de redistribuição de renda. In: BRESSERPEREIRA, L. C. (Org.). Populismo econômico: ortodoxia, desenvolvimentismo e populismo na América Latina. São Paulo: Nobel, 1991.

CARDOSO, E. Uma perspectiva macroeconômica do crescimento brasileiro: algumas comparações internacionais. In: ALMEIDA, Paulo Roberto de; BARBOSA, Rubens (Ed.). O Brasil e os Estados Unidos num mundo em mutação. Washington, DC, 2003.

; HELWEGE, A. Populismo, gastança e redistribuição. In: BRESSERPEREIRA, L. C. (Org.). Populismo econômico: ortodoxia, desenvolvimentismo e populismo na América Latina. São Paulo: Nobel, 1991.

CAVAlLO, D.; COTTANI, J. A.; KAHN, M. S. Real exchange rate behaviour and economic performance in LDCs. Economic Development and Cultural Change, v. 39, p. 61-76, Oct. 1990.

CEPAL. Una década de luces y sombras: América Latina y el Caribe en los años noventa. Cepal-Alfaomega, 2001.

CHANG, H. The East Asian development experience. In: CHANG, Ha-Joon (Ed.). Rethinking development economics. Anthem Press, 2003.

COLLIER, P.; BEVAN, D. L.; GUNNING, J. W. The political economy of poverty, equity and growth: Nigeria and Indonesia. A World Bank comparative study. Oxford: Oxford University Press, 1999.

CORDEN, W. M. Too sensational, on the choice of exchange rate regimes. Cambridge, MA: MIT Press, 2002.

DÍAZ-ALEJANDRO, C. Planos de estabilização no Cone Sul. In: BRESSER-PEREIRA, L. C. (Org.). Populismo econômico: ortodoxia, desenvolvimentismo e populismo na América Latina. São Paulo: Nobel, 1991.

DOLLAR, D. Outward-oriented developing economies really do grow more rapidly: evidence from 95 LDCs, 1976-1985. Economic Development and Cultural Change, v. 40, p. 523-544, 1992.

DOOLEY, M. P.; LANDAU, D. F.; GARBER, P. Interest rates, exchange rates and international adjustments. Nov. 2005. (NBER Working Paper, n. 11771).

An essay on the revived Bretton Woods System. Sept. 2003. (NBER Working Paper, n. 9971).

DORNBUSCH, R. Keys to prosperity: free markets, sound money and a bit of luck. Cambridge, MA: MIT Press, 2002.

; EDWARDS, S. The macroeconomics of populism. In: DORNBUSCH, R.; EDWARDS, S. (Ed.). The macroeconomics of populism in Latin America. Chicago: Chicago University Press, 1995.

; GOLDFAJN, I.; VALDES, R. Currency crises and collapses. Brookings

Papers on Economic Activity, Washington, n. 2, p. 219, 1995.

; PARK, Y. C. Flexibility or nominal anchors? In: COLLIGNON, Stefan; PISANI-FERRY, Jean; PARK, Yung Chul (Ed.). Exchange rate policies in emerging Asian countries. New York: Routledge, 1999. 
EDWARDS, S. Exchange rate misalignment in developing countries. The World Bank Research Observer, Washington, DC, Jan, 4, 1, 1989.

EASTERLY, W. The lost decades: developing countries' stagnation in spite of policy reform 1980-1998. Washington, DC: World Bank, 2001.

EICHENGREEN, B. Chinese currency controversies, presented to the Asian Economic Panel, 12-13 April, a revised and edited version is forthcoming in Asian Economic Papers, 2004.

; HATASE, M. Can a rapidly-growing export-oriented economy smoothly exit an exchange rate peg? Lessons for China from Japan's high-growth era. Cambridge, MA, Sept. 2005. (NBER Working Paper n. 11625).

ELSON, A. Reflections on the recent economic growth experience of East Asia and Latin America. London School of Economics, 2005. Mimeografado.

FAJNZYLBER, P.; LOAYZA, N.; CALDERÓN, C. Economic growth in Latin America and the Caribbean: stylized facts, explanations and forecasts. Washington, DC: The World Bank, 2002.

FISHLOW, A. O estado da Economia latino-americana. In: DESENVOLVIMENTO no Brasil e na América Latina, uma perspectiva histórica (1985). São Paulo: Paz e Terra, 2004.

; GWIN, C. Lessons from the East Asian Experience: overview. In: FISHLOW, Albert; GWIN, Catherine; HAGGARD, Stephan; RODRIK, Dani; WADE, Robert (Ed.). Miracle or design? Lessons from the East Asian experience. Washington, DC, 1994. (Overseas Development Council, Policy Essay, n.11).

FRENKEL, R. Real exchange rate and employment in Argentina, Brazil, Chile and Mexico. Buenos Aires: Cedes, 2004. Presented to the G24.

Argentina, a decade of the convertibility regime. Revista de Economia Política, v. 22, n. 4(88), Out./Dez. 2002.

; TAYLOR, L. Real exchange rate, monetary policy and employment. Revised version of a paper prepared for a High-Level United Nations Development Conference, New York, 14-15 Mar. 2005.

GALA, P.; LUCINDA, C. Exchange rate misalignment and growth: old and new econometric evidence. In: ENCONTRO NACIONAL DE ECONOMIA, 34, Salvador, Anpec, 2006.

GHURA, D.; GRENNES, T. The real exchange rate and macroeconomic performance in Sub-Saharan Africa. Journal of Development Economics, n. 42, p. 155-174, 1993.

HAUSMANN, R.; PRITCHETT, L.; RODRIK, D. Growth accelerations. John F. Kennedy School of Government, Harvard University, Draft, Apr. 2004.

LIM, J. Macroeconomic implications of the Southeast Asian crises. In: JOMO, K. S. (Ed.). After the storm: crisis, recovery and sustaining development in four Asian economies. Singapore University Press, 2004.

ONG, L. L. Burgernomics: the economics of the Big Mac standard. Journal of International Money and Finance, v.16, p. 865-878, 1997. 
ONG, L. L. Burgernomics and the ASEAN currency crisis. Journal of the Australian Society of Security Analysts, Autumn, p. 15-16, 1998.

PALMA, G. Gansos voadores e patos vulneráveis: a diferença da liderança do Japão e dos Estados Unidos no desenvolvimento do Sudeste Asiático e da América Latina. In: FIORI, José Luiz (Org.). O poder americano. Petrópolis, RJ: Vozes, 2005.

The three routes to financial crises: Chile, Mexico and Argentina [1]; Brazil [2], and Korea, Malaysia and Thailand [3]. In: CHANG, Ha-Joon (Org.). Rethinking development economics. Anthem Press, 2003.

PATEL, U. R. Some implications of real exchange rate targeting in India. New Delhi: Indian Council for Research on International Economic Relations, 1997.

POPOV, V.; POLTEROVICH, V. Accumulation of foreign exchange reserves and long term growth. Moscow, Russia: New Economic School, 2002. Unpublished paper.

RAJAPATIRANA, S.; ATHUKORALA, P. Capital inflows and the real exchange rate: a comparative study of Asia and Latin America. The World Economy, Oxford, Apr. 2003.

RAZIN, O.; COLLINS, S. Real exchange rate misalignment and growth. In: RAZIN, Assaf; SADKA, Efraim (Ed.). International economic integration: public economics perspectives. Cambridge, MA: Cambridge University Press, 1997/(NBER Working Paper, n. 6147).

RHEE, Y.; SONG, C. Exchange rate policy and effectiveness of intervention: the case of South Korea. In: COLLIGNON, Stefan; PISANI-FERRY, Jean; PARK, Yung Chul (Ed.). Exchange rate policies in emerging Asian countries. New York: Routledge, 1999.

RODRIK, D. Growth strategies. John F. Kennedy School of Government, Harvard University, Draft, Aug. 2004.

Exchange rate regimes and institutional arrangements in the shadow of capital flows. Presented on a Conference on Central Banking and Sustainable development, held in Kuala Lumpur, Malaysia in honor of Tun Ismail Mohamed Ali. Aug. 28-30, 2000.

King Kong meets Godzilla: the World Bank and The East Asian Miracle. In: FISHLOW, Albert; GWIN, Catherine; HAGGARD, Stephan; RODRIK, Dani; WADE, Robert (Ed.). Miracle or design? Lessons from the East Asian experience. Washington, DC: Overseas Development Council, 1994. (Policy Essay, n. 11).

SACHS, J. External debt and macroeconomic performance in Latin America and East Asia. Brookings Papers on Economic Activity, Washington, n. 2, 523-573, 1985.

Conflito social e políticas populistas na América Latina. In: BRESSERPEREIRA, L. C. (Org.). Populismo econômico: ortodoxia, desenvolvimentismo e populismo na América Latina. São Paulo: Nobel, 1991. p. 123-150, 1991.

TORNELL, A.; VELASCO, A. Financial crises in emerging markets: the lessons from 1995. Brookings Papers on Economic Activity, Washington, n. 1, p. 147-215, 1996.

SHATZ, H. W.; TARR, D. G. Exchange rate overvaluation and trade protection: lessons from experience. Washington, DC: Feb. 2000. (World Bank Policy Research Working Papers, n. 2289). 
STALLINGS, B.; PERES, W. Growth, employment and equity: the impact of economic reforms in Latin America and the Caribbean. ECLA, Brooking Institution Press, 2000.

WADE, R. Governing the market, economic theory and the role of government in East Asian industrialization. Princeton: Princeton University Press, 1990.

WILLIAMSON, J. Curbing the boom-bust cycle: stabilizing capital flows to emerging markets. Institute for International Economics, Jul. 2005. (Policy Analyses in International Economics, n.75).

Exchange rate policy and development. Presented in Initiative for Policy Dialogue Task Force on Macroeconomics. New York: Columbia University, 2003.

The case for a common basket peg for East Asian currencies. In: COLLIGNON, Stefan; PISANI-FERRY, Jean; PARK, Yung Chul (Ed.). Exchange rate policies in emerging Asian countries. New York: Routledge, 1999.

The crawling band as an exchange rate regime, lessons form Chile, Colombia and Israel. Washington, DC: Institute for International Economics, Oct. 1996.

WORLD BANK. The East Asian Miracle, economic growth and public policy. New York: Oxford University Press, 1993. 